\title{
O Partido dos Trabalhadores na Câmara dos Deputados: a evolução das bases socioeconômicas e territoriais (1994-2014)
}

Natalia Maciel

Tiago Ventura

\section{Introdução}

Em outubro de 2014, Dilma Rousseff reelegeu-se presidente da República do Brasil. O ineditismo nessa eleição foi a alternância na liderança dos candidatos nas pesquisas eleitorais. O que não houve de inédito foi a quarta vitória consecutiva do Partido dos Trabalhadores (PT), a disputa centralizada entre petistas e tucanos e a manutenção do padrão das bases eleitorais dos candidatos petistas desde as eleições de 2006.

As vitórias eleitorais do PT à presidência geraram diversos estudos na área de comportamento eleitoral, em especial os dedicados à mudança da base eleitoral na reeleição de Lula. Em síntese, esses estudos demonstram que a partir de 2006 os votos petistas migraram para estados das regiões Norte e Nordeste do país, distribuindo-se em municípios com menor renda per capita, indicadores mais baixos de desenvolvimento humano, menor população e menor taxa de urbanização. A variável explicativa destacada como mais importante dessa mudança foi o programa Bolsa Família ${ }^{1}$. O novo perfil das bases petistas se manteve nas eleições seguintes, quando o partido teve Dilma Rousseff como candidata (Carraro et al., 2007; Hunter e Power, 2007; Nicolau e Peixoto, 2007; Soares e Terron, 2008; Zucco, 2008; Singer, 2012; Zucco e Power, 2013; Zucco, 2013; Samuels e Zucco, 2014; Nicolau, 2015).

Esses estudos tiveram como foco o desempenho do PT nos pleitos presidenciais. No entanto, poucos trabalhos se dedicaram à análise dos resultados eleitorais do partido para a Câmara dos Deputados. Suprir essa lacuna é nosso objetivo. Pretendemos investigar a composição socioeconômica e demográfica dos votos do PT para a Câmara Federal no período compreendido entre 1994 e 2014. Nossa hipótese é de que a votação do partido para essa casa legislativa vem passando por mudanças em sua distribuição espacial e socioeconômica, afastando-se dos principais centros urbanos do país e caminhando rumo a cidades com tamanho populacional menor e renda per capita mais

1 Cf. Bonn (2011) para verificar uma posição contrária ao papel do Bolsa Família no ciclo eleitoral brasileiro. 
baixa. Esse movimento mostraria um reencontro, lento e gradativo, dos votos dos candidatos petistas à Câmara dos Deputados com o novo perfil da base eleitoral de seus candidatos à presidência.

A verificação dessa reaproximação eleitoral traz novos elementos a um dos principais debates recentes da ciência política brasileira: a relação entre o lulismo e o petismo. A compreensão de que a eleição de 2006 evidenciou um realinhamento eleitoral em torno da candidatura petista à presidência e de que essa alteração não foi seguida pela votação do partido no Legislativo sustenta o componente eleitoral do conceito de lulismo formulado por André Singer (2012). A mudança das bases socioeconômicas do voto dos candidatos petistas à Câmara dos Deputados destacada neste artigo pretende demonstrar que essa disjuntiva entre lulismo e petismo se limitou ao pleito de 2006. Ainda assim, nossos resultados indicam que a alteração das bases petistas para essa casa legislativa teve início já nesse ano.

O artigo dialoga com a literatura sobre a abordagem contextual do comportamento político e a geografia eleitoral a fim de trazer novos elementos e possibilidades de análise empírica para a discussão teórica sobre o lulismo e o petismo. Testamos nossa hipótese utilizando o município como unidade de análise e, em um primeiro momento, realizamos uma exploração descritiva das características demográficas dos municípios em que os candidatos a deputado federal do PT tiveram bom desempenho. Em um segundo momento, apresentamos modelos longitudinais que abarcam as seis eleições compreendidas no período entre 1994 e 2014. Testamos o impacto de variáveis socioeconômicas como renda per capita, densidade populacional, educação e porcentagem de população urbana na votação do PT para essa casa legislativa. Tendo em vista a literatura que analisa o efeito coattail entre a votação para cargos legislativos e a dos candidatos a postos executivos (Shugart e Carey, 1992; Cox, 1997, Samuels, 2003; Avelino, Biderman e Barone, 2012), incluímos variáveis políticas como presença de prefeito e governador do PT, votação do candidato a presidente e governador e a posição frente ao governo federal (oposição de 1994 a 2002 e situação de 2006 a 2014) como controles.

Os resultados confirmam nossa hipótese: as bases territoriais de apoio do PT no Legislativo federal apresentam mudanças em suas características socioeconômicas a partir do ano de 2006. Nos anos em que esteve na oposição o partido foi mais bem votado em municípios mais urbanizados e com maior renda per capita. No pleito em que Lula foi reeleito, a votação para a Câmara foi maior em municípios menos urbanizados e com menor renda, e as eleições que se seguiram mantiveram essa tendência. Testes complementares indicaram que o programa Bolsa Família não teve influência na votação para essa casa legislativa. Contudo, as variáveis políticas apresentaram forte impacto, sendo ainda mais relevantes que as socioeconômicas na explicação do desempenho eleitoral do partido. As análises descritivas demonstraram que também a partir de 2006 a votação dos candidatos petistas a deputado federal começou a crescer na região Nordeste em detrimento das regiões Sul e Sudeste. A eleição de 2014, por sua vez, foi a 
primeira em que o partido apresentou porcentagem de votação maior em cidades pequenas, com até 20 mil habitantes.

O artigo é composto por cinco seções, além desta "Introdução" e de uma "Conclusão". A seção "Bases eleitorais da votação dos candidatos à presidência e à Câmara dos Deputados do PT: dois fenômenos convergentes" é dedicada à revisão da literatura e à contribuição teórica trazida neste artigo para o debate sobre os conceitos de lulismo e petismo. Em "Abordagem contextual do comportamento eleitoral: o efeito do contexto espacial na decisão do voto", tratamos da literatura teórica sobre esse efeito e o que já sabemos sobre a geografia eleitoral das eleições para a Câmara no Brasil. Essa seção objetiva demonstrar a importância de levar em consideração o território nos estudos sobre comportamento eleitoral no Brasil. A seção "A votação do PT para a Câmara dos Deputados: uma análise descritiva de seis eleições" apresenta uma análise descritiva das características dos municípios em que o PT se destacou eleitoralmente. Em "Tratamento dos dados e métodos", descrevem-se os dados e os métodos que serão utilizados. Por fim, apresentamos os "Resultados dos modelos longitudinais". O artigo se encerra com uma pequena "Conclusão" acerca dos resultados, as consequências desses achados e os desafios futuros à melhor compreensão do desempenho eleitoral do PT.

\section{Bases eleitorais da votação dos candidatos à presidência e à Câmara dos Deputados do PT: dois fenômenos convergentes}

O lulismo e o petismo foram dois dos conceitos mais abordados na década recente pela ciência política brasileira, seja com análises considerando mais centralmente seus aspectos ideológicos (Rennó e Cabello, 2010; Ricci, 2010; Singer, 2012; Samuels e Zucco, 2014) ou aquelas dedicadas a interpretar as suas características do ponto de vista do comportamento político dos eleitores (Nicolau e Peixoto, 2007; Carraro et al., 2007; Hunter e Power, 2007; Zucco, 2008).

André Singer (2012) foi pioneiro na produção acadêmica nesse tema. O autor define o lulismo como um realinhamento eleitoral ocorrido nas eleições de 2006. Setores mais empobrecidos da sociedade brasileira aderiram à figura do presidente Lula como resultado da escolha, no primeiro mandato, de uma agenda de redução da miséria e manutenção da ordem econômica. Os setores mais escolarizados e de maior renda, base tradicional da eleição de Lula em 2002, afastaram-se em decorrência das denúncias de corrupção em 2005.

Para Singer, o PT não acompanhou a inserção de seu candidato à presidência da República nas camadas mais populares, pois ainda manteve suas bases eleitorais tradicionais nas eleições de 2006. No aspecto ideológico, o petismo também ocuparia espaço distinto da gramática moderada do lulismo, mantendo, ainda que de forma conflituosa, traços programáticos mais radicais, característicos do seu processo de fundação. Em outras palavras, o petismo e o lulismo teriam ocupado espaços ideológicos e eleitorais distintos. 
No entanto, o autor prevê para o período pós-2006 um movimento crescente de adesão do petismo ao lulismo, ou seja, de encurtamento entre a distância ideológica e eleitoral entre esses dois movimentos. Esse fenômeno já seria perceptível em estudos que indicam a perda da identificação ideológica de simpatizantes do PT com a esquerda e o crescimento do apoio ao partido nas classes mais populares e menos escolarizadas (Veiga, 2007; Venturi, 2010; Samuels, 2006).

A maior parte das críticas recebidas por Singer foca na refutação da tese da separação operada entre lulismo e petismo. Samuels e Zucco (2014) condensam parte importante dessa literatura. Os autores definem o lulismo como um sentimento fraco ideologicamente e derivado em grande parte de avaliações retrospectivas ligadas ao desempenho governamental de Lula no primeiro mandato. Tal conclusão baseia-se tanto em estudos que indicam convergências entre a ideologia dos simpatizantes de Lula e as bandeiras históricas do PT (Nunes, Giani e Resende, 2010; Samuels, 2006) como em pesquisas de opinião que evidenciam a convergência ideológica entre simpatizantes de Lula e simpatizantes do PT (Rennó e Cabello, 2010). Tais achados refutariam parte da tese de Singer de que petismo e lulismo teriam bases ideológicas distintas. Para os autores a base ideológica de ambos os fenômenos é a mesma: a construção de uma estratégia não revolucionária para a ampliação da igualdade e da participação política na democracia brasileira.

Resta a Samuels e Zucco explicarem a segunda parte da tese de Singer que se refere à separação eleitoral entre Iulismo e petismo nas eleições de 2006. Eles o fazem recorrendo à tese de que em sistemas presidencialistas multipartidários haveria uma tendência de eleitores pobres atribuírem a responsabilidade pelas melhorias em suas condições de vida ao presidente em exercício e não ao seu partido. Portanto, a compreensão do lulismo e do petismo como um movimento ideológico de raízes similares não deveria levar à conclusão de que apoiadores da figura pública do presidente Lula se converteriam automaticamente em simpatizantes do PT como consequência do sistema multipartidário e presidencialista brasileiro. Segundo os autores, estaria em curso uma tendência, incentivada pela direção do partido, de se aproximar cada vez mais do perfil do eleitor lulista, investindo na expansão de sua estrutura partidária e sua base de filiados. Se bem-sucedida, tal estratégia levaria ao encurtamento da distância percebida nas eleições de 2006 entre os eleitores dos presidenciáveis petistas e seus candidatos à Câmara Federal, fazendo com que lulismo e petismo conformassem um movimento mais próximo do ponto de vista eleitoral.

Em síntese, apesar da divergência no diagnóstico, os dois estudos preveem futuro semelhante ao PT. Seja por esforço partidário, como indicam Samuels e Zucco (2014), seja por pressão do discurso conciliador promovido pelo lulismo no interior do PT, como aponta Singer (2012), os anos seguintes seriam de crescente aproximação entre os apoiadores do partido e os apoiadores de seus candidatos à presidência. Investigar se tal aproximação se materializou do ponto de vista eleitoral é um desafio ainda ausente na literatura, por isso constitui-se objetivo deste artigo. Sua comprovação 
é central para a compreensão da dinâmica atual do PT. O partido mudou seu perfil eleitoral? Afastou-se de seus espaços tradicionais de atuação? O petismo e o lulismo se reencontraram do ponto de vista eleitoral? São perguntas ainda em aberto.

Há um estudo dedicado exclusivamente a esse tema - As bases eleitorais de Lula e do PT: do distanciamento ao divórcio (Terron e Soares, 2010). Terron e Soares (2010) demonstram, a partir da utilização de técnicas de econometria espacial, que houve uma separação no território eleitoral ocupado por Lula e pelo PT e concluem que existiu um divórcio entre lulismo e petismo em 2006. Outros trabalhos, que trataram a votação do PT para a Câmara somente de forma lateral, chegaram às mesmas conclusões: a mudança da geografia do voto em Lula não influenciou a votação petista para a Câmara dos Deputados nessa eleição (Hunter e Power, 2007; Zucco, 2008).

Acreditamos, contudo, que essa explicação é um retrato específico das eleições de 2006. Cabe investigar se, ao incorporar as eleições de 2010 e 2014 nas análises, os votos do PT para a Câmara convergiram ou não rumo às novas bases eleitorais de seus candidatos à presidência.

\section{Abordagem contextual do comportamento eleitoral: o efeito do contexto espacial na decisão do voto}

O comportamento eleitoral é frequentemente analisado com base em uma abordagem composicional, na qual características e atitudes individuais do eleitor - tais como suas preferências partidárias, classe, situação econômica, religião, avaliação retrospectiva e futura das propostas do governo - são os principais fatores que influenciam a decisão do voto. Contudo, apesar de o comportamento ser um atributo individual, eles são desenvolvidos em contextos históricos, sociais e geográficos específicos. Nesse sentido, decisões políticas também são influenciadas por elementos do meio e das relações sociais às quais os indivíduos estão vinculados em suas vidas diárias (Agnew, 1996; Johnston e Pattie, 2006; Terron, 2012).

A abordagem contextual do comportamento eleitoral é complementar à abordagem composicional pois entende que relações sociais devem ser analisadas ao longo do tempo e do espaço e, ao mesmo tempo, vinculadas à produção de atitudes e comportamentos individuais. Indivíduos são influenciados em algum grau pelo contexto espacial dos lugares em que vivem quando tomam decisões políticas (Agnew, 1996). O contexto pode influenciar de diferentes formas a escolha do voto: pela observação das condições socioeconômicas locais; pelo contato com os vizinhos em redes sociais interpessoais; por meio do fluxo de informação pelas mídias locais; pelas estratégias de campanha de partidos e políticos nas localidades, entre outras formas (Johnston e Pattie, 2006).

O processo de interação social nos arredores de onde os indivíduos vivem é denominado pela abordagem contextual como efeito de vizinhança. Esse processo envolve uma interação interpessoal em que há uma "conversão por conversação": 
pessoas que interagem entre si continuamente tendem a ter comportamentos e tomar decisões políticas similares (Johnston e Pattie, 2006). A composição social do contexto cria atalhos informacionais enviesados pelas características específicas daquele espaço, que, por sua vez, moldam a forma como as pessoas compreendem a política. Como resultado, os indivíduos desenvolvem uma alta sensibilidade para os atalhos informacionais de classe, que influenciam os julgamentos que eles fazem sobre os seus arredores sociais (Burbank, 1995).

O contexto espacial é um fator que deve ser considerado ao se analisar o comportamento eleitoral no sistema proporcional de lista aberta brasileiro. A campanha eleitoral para as cadeiras da Câmara dos Deputados é uma disputa por espaço. Esse espaço pode ser ideológico, no entanto, com frequência trata-se de espaço físico, já que campanhas são desenhadas e implementadas tendo em vista o território (Ames, 2003). Nesse mesmo espaço físico, o eleitor decide o seu voto influenciado, entre outros fatores, pelo contexto socioeconômico e político de sua localidade.

Estudos sobre a geografia do voto comprovam que indicadores sociais e econômicos são variáveis importantes para compreender as bases territoriais dos partidos políticos na Câmara dos Deputados. Soares (1973) demonstra que os partidos políticos do período democrático de 1946 a 1964 refletiam uma divisão não apenas econômica regional do Brasil, mas também das classes sociais que compunham essas regiões. Partidos conservadores como o Partido Social Democrático (PSD) e a União Democrática Nacional (UDN) tinham maior ganho eleitoral em áreas rurais e subdesenvolvidas, enquanto partidos de esquerda, como o Partido Trabalhista Brasileiro (PTB) e o Partido Comunista Brasileiro (PCB), recebiam maior apoio de regiões urbanizadas e desenvolvidas da região Sudeste. Soares acreditava que o comportamento não ideológico das regiões subdesenvolvidas do país, onde o eleitorado rural era manipulado pelas elites conservadoras, iria se reverter como resultado da intensificação da urbanização e da industrialização dessas áreas.

Ao analisar a relação entre as bases territoriais dos partidos contemporâneos e as atividades legislativas de seus deputados federais, Carvalho (2003) demonstra que parlamentares que recebem maior quantidade de votos em capitais apresentam comportamento legislativo mais universalista e programático, enquanto os que são mais bem votados em cidades do interior apresentam comportamento mais particularista e localista. O autor destaca que a dicotomia capital/interior apresenta uma forte descontinuidade nos indicadores sociais como índice de desenvolvimento humano, educação, renda e urbanização. Todos esses indicadores são maiores nas capitais e grandes cidades, o que sugere uma relação entre o tamanho populacional dos municípios e os indicadores sociais.

Ao mesmo tempo, deputados com bases territoriais de apoio em grandes cidades têm incentivo a desenvolver um comportamento parlamentar mais universalista, já que um eleitorado muito numeroso desincentiva atividades legislativas particularistas por ser difícil cobrar crédito por elas. O inverso ocorre em cidades menores: o eleitorado mais 
reduzido incentiva a atividade legislativa particularista, já que a conexão eleitoral direta com o eleitor é facilitada (Carvalho, 2003). O autor demonstra que a distribuição das bases eleitorais dos partidos nas eleições para a Câmara dos Deputados nos anos de 1994 e 1998 apresenta um padrão bem definido segundo a dicotomia capital/interior. Partidos ideológicos, como o PT, recebiam maior apoio eleitoral nas capitais, enquanto partidos considerados catch-all, como o PMDB e o então PFL (atualmente DEM), tinham maior votação em municípios do interior.

Sobre a geografia eleitoral específica da votação do PT para a Câmara dos Deputados, Terron e Soares (2010) realizam um estudo, utilizando o município como unidade de análise, para demonstrar o "divórcio" entre as bases eleitorais de Lula e do PT. Os autores inovam ao utilizarem o método estatístico espacial com o objetivo de subsidiar a discussão sobre petismo e lulismo com base em uma investigação espaçotemporal. Eles demonstram com análise descritiva de dados que a votação de Lula aumentou de 1994 a 2006. Em contrapartida, apesar de ter melhorado o seu desempenho na Câmara ao longo do tempo, os autores verificam uma redução na votação do partido para essa casa legislativa, principalmente no ano de 2006. A diferença em pontos percentuais da votação para a presidência e para a Câmara aumenta gradualmente de 1994 a 2006.

A comparação entre os territórios eleitorais de Lula e do PT é feita por Terron e Soares (2010) por meio de índices de correlação espacial bivariado de Moran e por regressões espaciais. A análise dos municípios em que há coincidência de votação alta em Lula e no PT, indicado pelos clusters do índice de Moran Local, demonstra que existe um aumento do número de municípios que consistem em territórios eleitorais de ambos entre 1994 e 1998, enquanto a estatística não é significativa para os anos de 2002 e 2006.

Ao analisarem a espacialização do voto separadamente, os autores mostram que na eleição de 2002 a votação de Lula se diferencia da dos deputados por conta do seu aumento e expansão territorial. O candidato à presidência passou a depender menos dos territórios eleitorais do PT e a conquistar mais votos em municípios onde os candidatos a deputado não conseguiram o mesmo desempenho. Em 2006 os territórios eleitorais em comum reduzem drasticamente, passando de 401 para 115 municípios (Terron e Soares, 2010 , p. 325 e 326). Nesse sentido, os autores concluem que o desempenho eleitoral de Lula e do PT tem agentes promotores distintos. Eles levantam a hipótese de que "o petismo permanece ligado ao ativismo político e às organizações comunitárias", enquanto a expansão territorial de Lula teve como principal responsável o programa Bolsa Família, principalmente para o Norte e Nordeste do país. O programa "cria um vínculo entre o eleitor e o presidente sem a intermediação de outros atores políticos, e permite uma aproximação maior com os prefeitos, independente de partido" (Terron e Soares, 2010, p. 334).

Nesse sentido, a análise das bases territoriais e de sua composição socioeconômica aparece como fator importante para desvendar aspectos do 
comportamento eleitoral e da formação dos partidos políticos no Brasil. A importância dessa abordagem é a primeira defesa teórica que pretendemos fazer. Este artigo se insere nessa tradição de estudos de comportamento eleitoral no Brasil nos quais o território eleitoral e suas características socioeconômicas são fator importante de análise. Nesse sentido, os métodos aqui empregados utilizarão dados agregados no nível dos municípios com vistas a entender alterações nas bases eleitorais do $\mathrm{PT}^{2}$.

\section{A votação do PT para a Câmara dos Deputados: uma análise descritiva de seis eleições}

O PT ampliou consideravelmente a sua presença na Câmara dos Deputados nas últimas seis eleições. Essa ampliação, contudo, não foi constante, apresentando recuos e avanços ao longo do tempo. O Gráfico 1 mostra a tendência crescente da presença do partido nessa casa legislativa nas eleições da década de 1990, alcançando o seu ápice em 2002, ano em que chega à presidência da República com a eleição de Lula. O PT perde representação na Câmara nas eleições de 2006, com a redução de sete deputados em relação à legislatura anterior ${ }^{3}$, provavelmente como consequência do escândalo de corrupção do Mensalão, que veio à tona em 2005 (Singer, 2012). Houve uma breve recuperação no número de eleitos no ano de 2010, porém, o decréscimo foi considerável em 2014, totalizando 69 deputados eleitos.

\footnotetext{
${ }^{2}$ A discussão proposta neste artigo não busca compreender os motivos individuais do eleitor em votar no PT. Se assim o fosse, caberia o uso de dados composicionais para não incorrer no que a literatura conceitua como falácia ecológica. Nosso objetivo é identificar a mudança das características socioeconômicas das bases eleitorais, compreendidas como bases territoriais de apoio do PT ao longo das últimas seis eleições, com foco particular no desempenho do partido no Legislativo federal.

${ }^{3}$ A comparação leva em conta o número de deputados no momento da posse. Não foram consideradas possíveis migrações partidárias ao longo das legislaturas.
} 


\section{Número de deputados do PT eleitos para a Câmara por ano eleitoral no momento da posse}

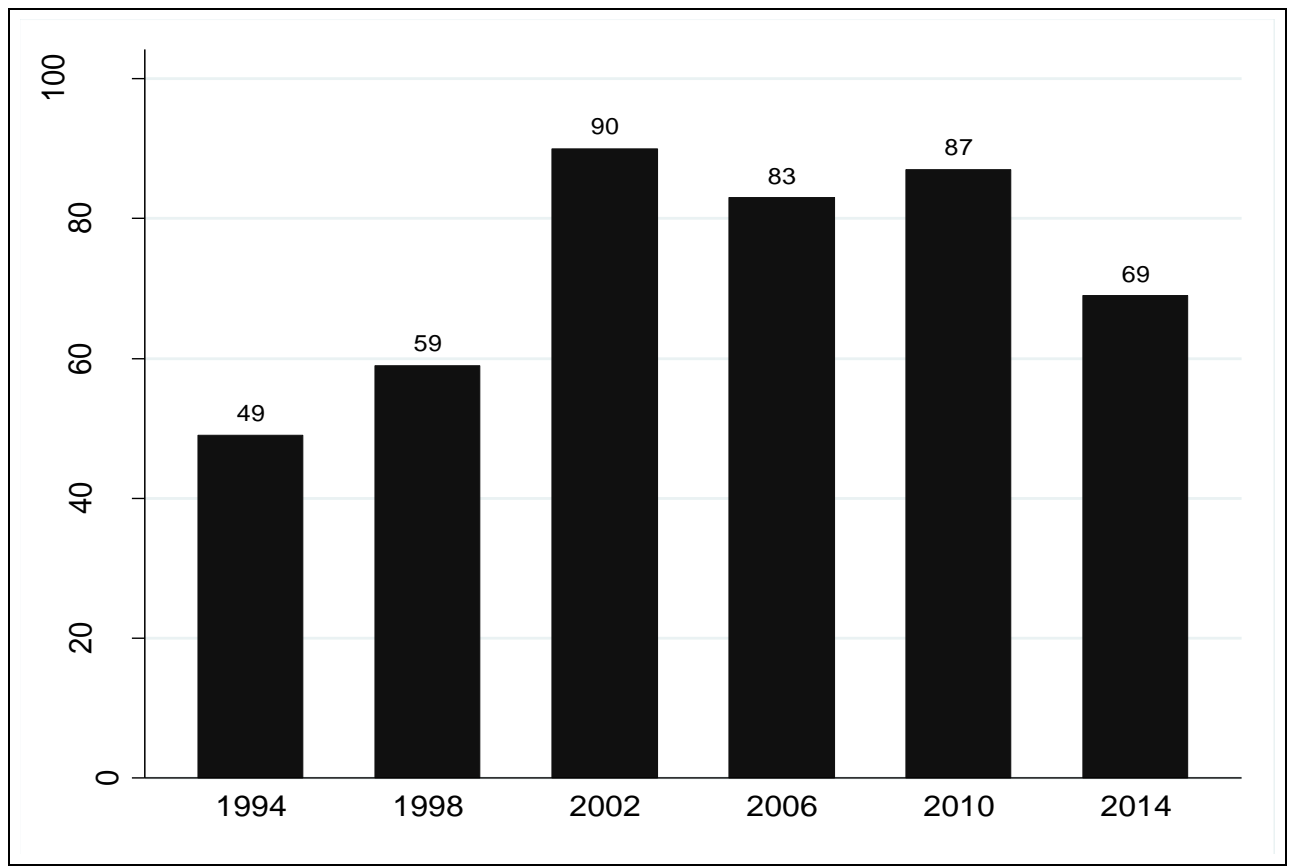

Fonte: Câmara dos Deputados. Elaboração dos autores.

A votação do partido para a Câmara dos Deputados apresenta evolução semelhante. O Gráfico 2 mostra uma crescente votação do partido entre os anos de 1994 e 2002. Em 2006 houve uma pequena redução, seguida de uma recuperação em 2010 e um decréscimo na votação de 2014. Apesar da queda no último ano, a votação do PT nos munícipios permanece em patamares superiores aos observados na década de 1990. 


\section{Gráfico 2 \\ Votação total do PT (nominal e legenda - em milhões de votos) para a Câmara dos Deputados por ano}

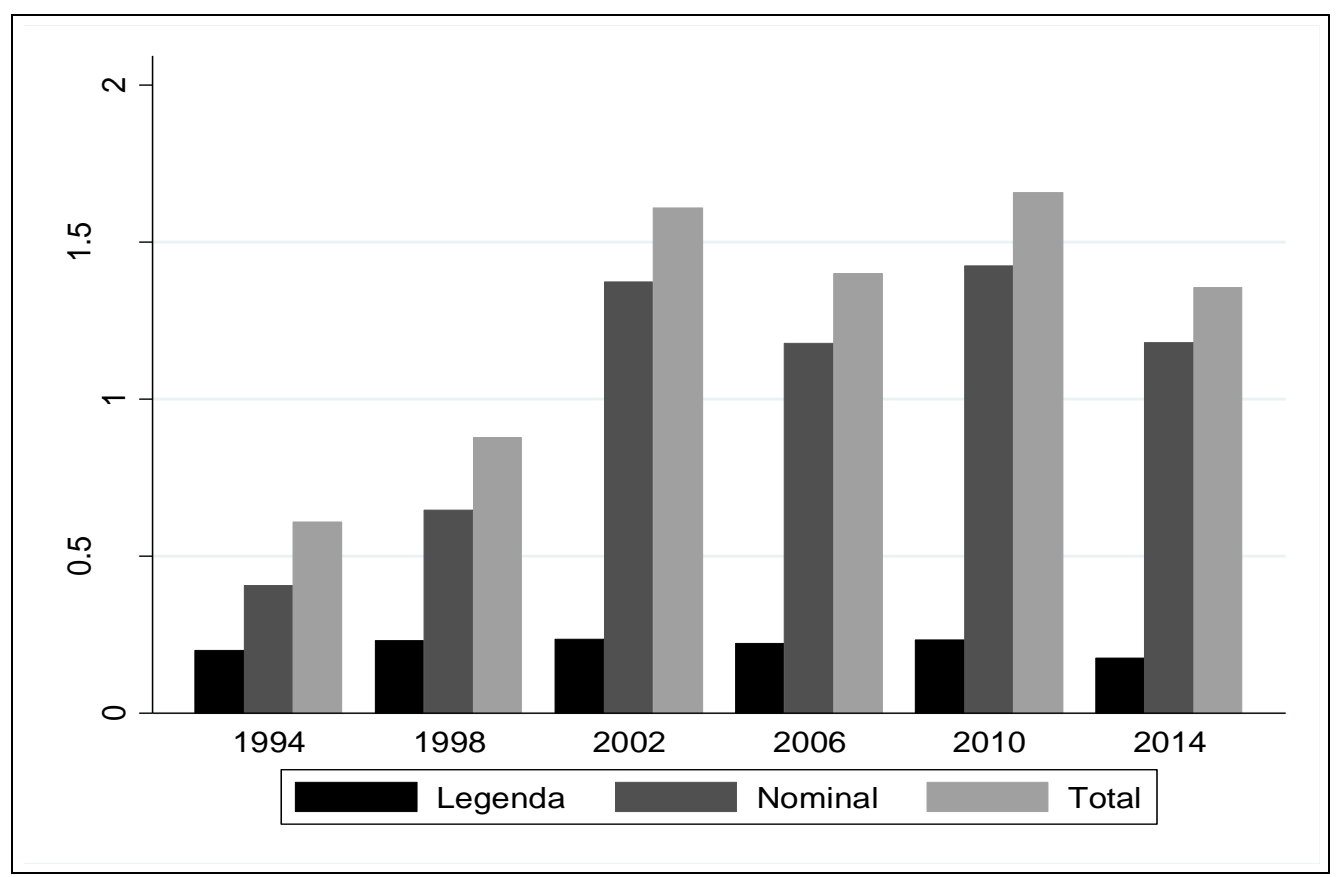

Fonte: TSE, CEM/Cebrap. Elaboração dos autores.

Atestada a tendência de crescimento da votação e do número de cadeiras do partido na Câmara nas últimas seis eleições, cabe analisar onde esse crescimento foi mais importante, ou seja, qual é o perfil dos municípios que mais contribuíram para o desempenho eleitoral do PT na votação para a Câmara dos Deputados. Essa análise serve ao objetivo de compreender se há uma mudança nas características demográficas dos municípios em que o PT atingiu melhor desempenho ao longo das seis eleições. $O$ Gráfico 3 apresenta a evolução em anos da porcentagem média de votação do partido nos municípios, que foram divididos por faixas de população: 


\section{Gráfico 3 \\ Porcentagem média da votação do PT para a Câmara dos Deputados nos municípios por faixas de população e ano}

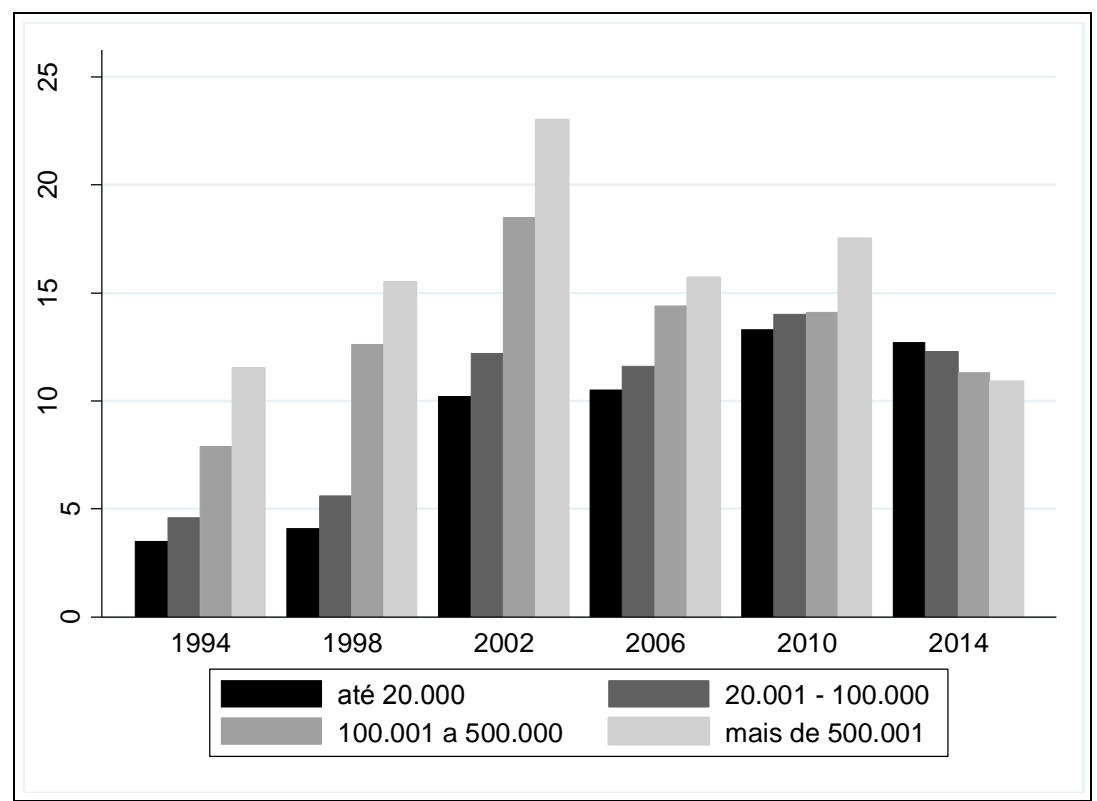

Fonte: TSE, CEM/Cebrap, IBGE. Elaboração dos autores.

Podemos observar que nos primeiros anos analisados, entre 1994 e 2006, o PT recebeu percentual maior de votação em cidades maiores, com mais de 100.000 habitantes. O ano de 2010 começa a apresentar uma mudança nessa tendência; o partido tem praticamente a mesma votação média nos municípios das primeiras três faixas de população, apesar de ainda ser mais votado nas cidades com mais de 500.000 habitantes.

O ano de 2014 apresenta uma mudança importante na base demográfica da votação do PT: pela primeira vez o partido passa a ser mais votado em cidades menores. Ele é ligeiramente mais votado nos municípios com até 20.000 habitantes, seguido dos municípios da segunda faixa que compreende as cidades entre 20.001 e 100.000 habitantes. Os dados indicam que a partir de 2006, o PT passa a melhorar paulatinamente seu desempenho em municípios com menor população. Essa mudança é mais acentuada na eleição de 2014. Por outro lado, nesse mesmo ano o partido reduziu seu desempenho nas cidades com mais de 500.000 habitantes. Esses resultados convergem com os diagnósticos realizados sobre os votos de Lula e sua relação com o tamanho da população dos municípios (Nicolau e Peixoto, 2007).

A análise descritiva da votação segundo o tamanho populacional da cidade indica uma mudança na votação do PT rumo a municípios com menor população. Cabe investigar se houve alteração importante dessa distribuição entre as regiões do país, 
conforme ocorrido com os votos dos candidatos à presidência do partido. O Gráfico 4 mostra a porcentagem média da votação do partido nas cinco regiões por ano eleitoral:

Gráfico 4

Porcentagem média da votação do PT para a Câmara dos Deputados nos municípios por região e ano

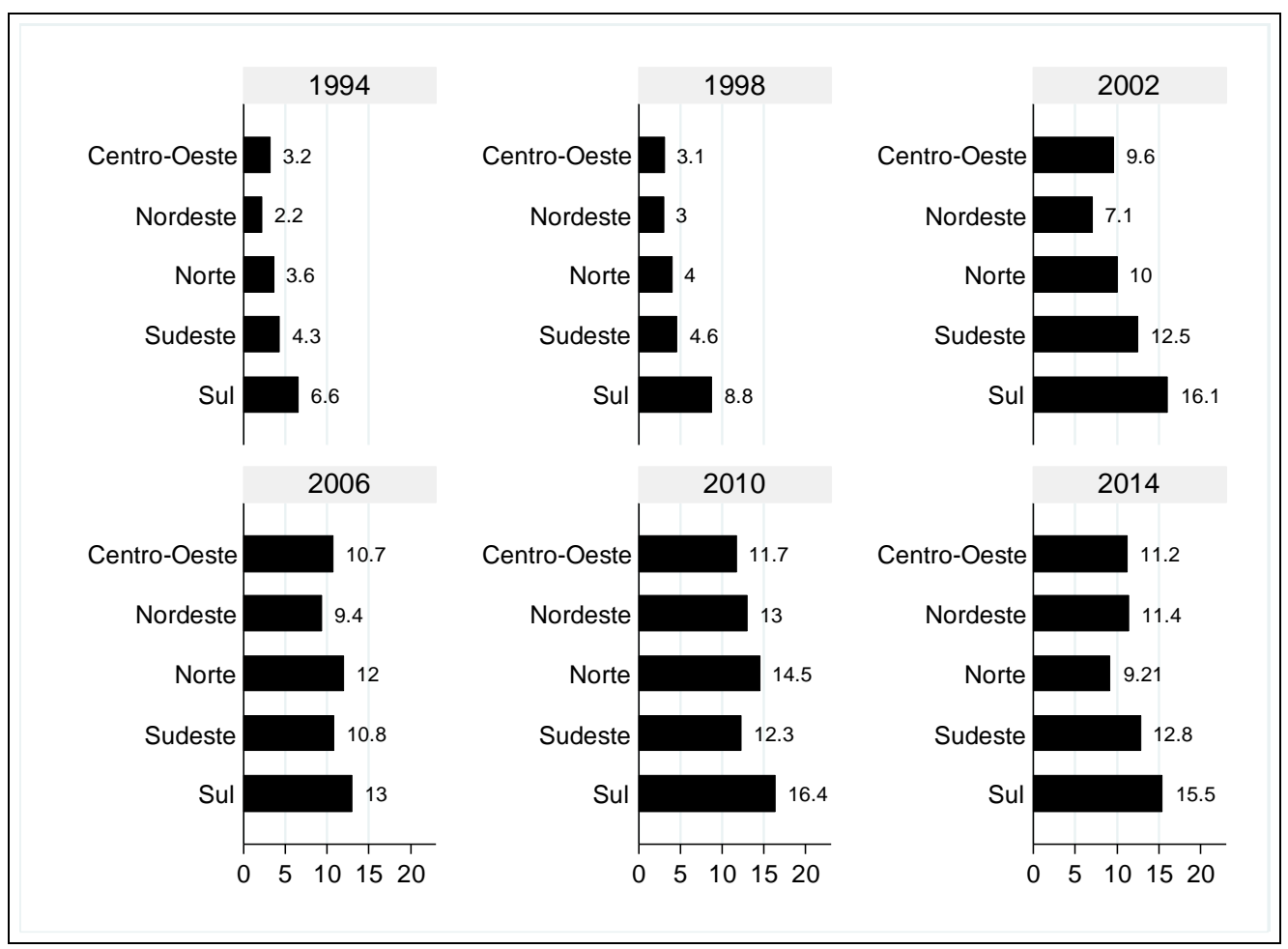

Fonte: TSE, CEM/Cebrap, IBGE. Elaboração dos autores.

A porcentagem média da votação nas regiões mostra algumas diferenças importantes. Entre 1994 e 2002, os municípios das regiões Sul e Sudeste apresentaram porcentagem maior de votos no PT quando comparados com os de outras regiões do Brasil. Em 2002, o PT melhora seu desempenho em todas as regiões, apesar de o Sul e o Sudeste manterem sua liderança. A partir de 2006, essa diferença regional começa a se reduzir com o Centro-Oeste e o Nordeste crescendo de forma mais consistente. Por exemplo, em 2010, a votação nos municípios da região Nordeste ultrapassa a dos municípios do Sudeste em termos percentuais, ficando atrás somente da região Sul.

No entanto, uma vez que a competição no sistema eleitoral proporcional de lista aberta é bastante acirrada, as porcentagens das votações para a Câmara nos municípios não são altas como nas eleições majoritárias para cargos executivos. Dessa forma, a variação percentual não é alta. Assim, propomos analisar a votação no nível municipal levando em consideração cidades onde o PT teve desempenho acima de sua média 
nacional a fim de verificar em quais regiões o aumento foi mais relevante. Para isso identificamos os municípios em que o partido teve votação acima de um desvio-padrão de sua média e, a seguir, determinamos as regiões em que se localizam esses municípios. Por fim, calculamos a porcentagem que eles representam do total dos municípios da região. O resultado é apresentado no Gráfico 5:

\section{Gráfico 5}

Porcentagem de municípios por região com votação no PT com valor igual ou maior que um desvio-padrão acima da média

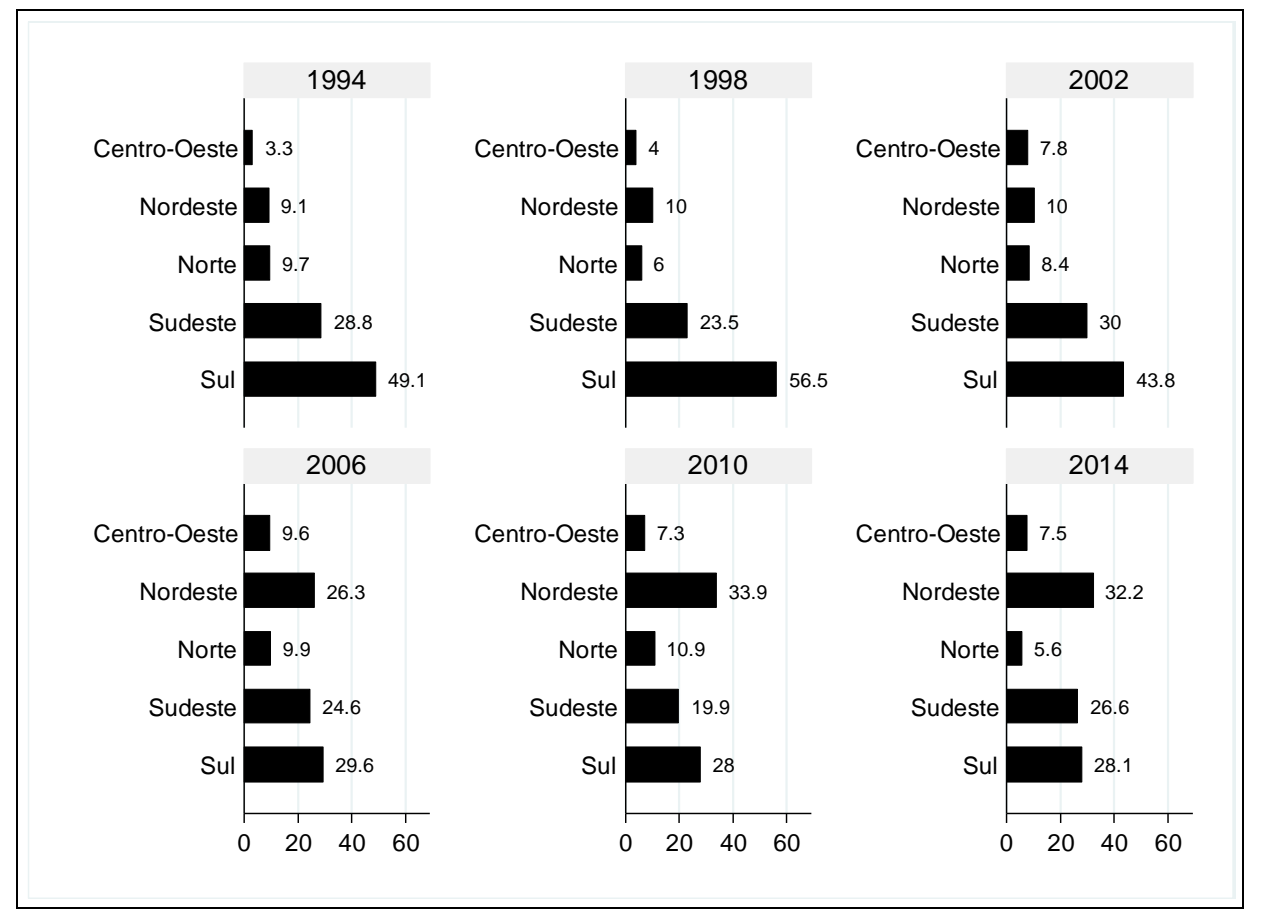

Fonte: TSE, CEM/Cebrap, IBGE. Elaboração dos autores.

Observamos no Gráfico 5 que entre os anos de 1994 e 2002 as bases territoriais de apoio do PT se concentravam nas regiões Sul e Sudeste. A partir de 2006 os municípios da região Nordeste passam a despontar como territórios importantes para o partido, enquanto as regiões Sul e Sudeste chegam a perder metade do território eleitoral. Essas duas regiões continuam apresentando porcentagens de votação altas com relação às demais, contudo, em comparação com as primeiras três eleições, a perda de municípios com alta votação no PT é significativa. Em contrapartida, a legenda ampliou em três vezes a sua presença no Nordeste nas últimas três eleições, convergindo, portanto, com os resultados encontrados acerca do voto nos candidatos petistas à presidência (Nicolau e Peixoto, 2007; Soares e Terron, 2008; Nicolau, 2015). A diferença está na região Norte do país, em que o partido não acompanha o bom desempenho de seus candidatos à presidência. 
Em suma, a análise descritiva demonstra um crescimento da votação do PT por todo o país. A porcentagem média da votação nos municípios cresce em cidades com menor número de habitantes, a partir de 2006. Em 2014, pela primeira vez, o PT tem desempenho eleitoral superior em cidades com menos de 20.000 habitantes. Além disso, a partir de 2006 os municípios do Nordeste tornam-se, gradativamente, os territórios de melhor desempenho na votação do partido para Câmara dos Deputados. Em suma, os votos do PT passam a migrar para municípios da região Nordeste e para cidades com tamanho populacional menor, seguindo, com peculiaridades, a trajetória do voto dos candidatos à presidência.

\section{Tratamento dos dados e métodos}

A fim de analisar o desempenho eleitoral do PT e o efeito de variáveis socioeconômicas e políticas, construímos um banco em painel em que as unidades de análise são os municípios em cada ano eleitoral. Uma vez que o número de unidades varia por causa da criação de municípios durante o período analisado, fizemos uma adaptação para que todos os anos tivessem os mesmos municípios, o que permite a comparação ao longo do tempo. Utilizamos a malha municipal de 2007 com 5.564 municípios, para a qual existem códigos de compatibilização entre os municípios de origem e os criados entre os anos de 1994 e $2006^{4}$. Ajustamos o banco repetindo os dados dos municípios de origem para os municípios criados a partir deles. Para os municípios que surgiram a partir de mais de um município de origem, repetimos os dados do primeiro município de origem. No total foram 543 municípios ajustados, totalizando menos de $2 \%$ do banco de dados. Os seis municípios criados a partir de 2010 não foram acrescentados na análise. Após o ajuste obtivemos um banco em painel com um total de 33.384 casos (5.564 municípios em seis eleições).

Para avaliar o efeito das características socioeconômicas dos municípios sobre o voto do PT para a Câmara, foram incluídas as seguintes variáveis: porcentagem de população urbana, densidade populacional $(\log )^{5}$, escolaridade (porcentagem de adultos com 18 anos ou mais que completaram o ensino fundamental) e renda per capita (log). Os dados dos anos de 1994, 2002 e 2010 são referentes aos censos 1991, 2000 e 2010, respectivamente. Esses dados foram interpolados para os anos de 1998 e 2006 . Para 2014 foram repetidos os dados do censo 2010.

\footnotetext{
${ }^{4}$ Agradecemos a Sonia Terron por ter cedido os códigos de compatibilização do IBGE.

5 Preferimos utilizar a variável densidade populacional em vez de simplesmente população, pois ela acrescenta o território como fator para a análise. Ao medir o número de habitantes por quilômetro quadrado temos uma dimensão da concentração dos indivíduos no território. A concentração ou dispersão dos indivíduos tem implicações na conexão eleitoral entre candidatos e eleitores e na percepção dos indivíduos quanto às condições sociais, econômicas e políticas do espaço territorial em que eles vivem, como já discutido anteriormente. Além disso, em conjunto com a variável população urbana, ela permite inferir se estamos tratando de cidades do interior ou de grandes metrópoles, de forma a criar uma interseção com o debate teórico sobre geografia eleitoral.
} 
Também incluímos variáveis políticas como controles. Esperamos que a presença de membros do partido em cargos executivos ajude a alavancar as votações para a Câmara. Estudos anteriores já trataram da influência que as eleições presidenciais exercem sobre os pleitos para o Legislativo federal (Shugart e Carey, 1992; Cox, 1997). A associação com candidatos à presidência fortes rende benefícios aos candidatos ao Legislativo como suporte organizacional e acesso potencial ao futuro governo federal.

Especificamente no caso brasileiro, Samuels (2003) argumenta que ocorre um efeito coattail entre a votação dos candidatos ao governo do estado e a dos candidatos à Câmara dos Deputados. A escolha dos candidatos que comporão a lista do partido acontece no estado, de forma que aqueles que desejam concorrer nas eleições para a Câmara devem se aproximar dos líderes políticos do seu distrito. Após entrar na lista os candidatos buscam recursos para impulsionar suas campanhas associando suas candidaturas à do candidato ao governo do estado. Campanhas para o Executivo estadual fornecem três tipos de benefícios para os candidatos à Câmara: atalhos informacionais, recursos organizacionais e exposição na mídia.

Avelino, Biderman e Barone (2012), por sua vez, comprovaram um efeito coattail reverso entre a eleição para o cargo de prefeito no ano de 2008 e a votação do seu partido nas eleições proporcionais estaduais no ano de 2010. Para os autores, "essa vantagem poderia vir do maior acesso dos prefeitos aos recursos públicos, do seu papel como implementadores de políticas públicas locais, como intermediários de transferências estaduais e federais, como emprestadores de credibilidade para as promessas eleitorais dos candidatos do partido, ou uma combinação desses diferentes aspectos" (p. 1.005).

Tendo em vista as evidências quanto ao efeito de variáveis políticas sobre a votação para a Câmara, incluímos nos modelos as porcentagens de votação recebidas pelo candidato do PT à presidência e aos governos de estado no primeiro turno de cada eleição. Também foram incluídas dummies para a posição frente ao governo federal (oposição entre 1994 e 2002 e situação entre 2006 e 2014), para a presença de governador de estado e de prefeito do município do PT no momento da eleição.

Elaboramos modelos complementares a fim de verificar o efeito do programa Bolsa Família sobre o voto. Nosso objetivo é avaliar se essa política apresenta impacto na votação para a Câmara assim como para os pleitos presidenciais. Para isso criamos uma variável que busca medir o impacto do recebimento do benefício sobre a renda per capita dos municípios. Usamos a média do valor recebido pelo município nos anos anteriores à eleição e dividimos pelo valor de sua renda per capita ${ }^{6}$. Com isso estamos tentando

\footnotetext{
${ }^{6}$ Nessa média foi incluído o valor total do Bolsa Família recebido no ano da eleição. O banco de dados fornecido pelo Ministério da Assistência Social discrimina o valor total recebido em cada ano, não sendo possível retirar desse montante o valor referente aos meses de novembro e dezembro, ou seja, os meses após as eleições. No entanto, os valores recebidos no ano eleitoral são de suma importância e não poderiam ser retirados da análise. Assim, optamos por incluir o valor total recebido no ano eleitoral no cálculo das médias, mesmo que os valores recebidos nos dois últimos meses do ano não tenham influência
} 
avaliar qual é o efeito do impacto do programa sobre a renda na votação do partido na Câmara.

Dados temporais organizados em painel podem violar os pressupostos da regressão de mínimos quadrados ordinários (OLS) de homocedasticidade e ausência de autocorrelação do termo de erro. Para superar essas dificuldades elaboramos modelos de mínimos quadrados generalizados com efeitos fixos, que controlam a heterogeneidade das variáveis não observadas no modelo que são constantes ao longo do tempo ${ }^{7}$. 0 modelo é representado matematicamente na equação a seguir:

\section{Equação 1:}

$y_{i t}=\mu_{t}+\beta X_{i t}+\alpha_{i t}+\varepsilon_{i t}$

Onde:

$i=1, \ldots, 5564$ municípios, analisados em seis grupos de anos eleitorais

$t=$ tempo, que são os seis anos eleitorais (1994, 1998, 2002, 2006, 2010 e 2014).

$X=$ conjunto de variáveis independentes

$\alpha=$ efeito fixo

$\varepsilon=$ erro-padrão

Os modelos longitudinais, no entanto, analisam o efeito das variáveis no conjunto dos anos. Para verificar se houve continuidade ou mudança nesses efeitos ao longo do tempo, elaboramos modelos complementares com interações entre variáveis dummies que indicam os anos eleitorais e cada uma das variáveis socioeconômicas.

Interações multiplicativas podem ser utilizadas quando houver uma hipótese condicional em que se espera que a relação entre duas ou mais variáveis dependa do

na decisão do voto no momento das eleições no mês de outubro. Os valores do programa Bolsa Família estão ajustados para valores reais de 2010 .

${ }^{7} \mathrm{O}$ termo $\alpha_{i t}$ é o efeito combinado na variável dependente $y$ de todas as variáveis não observadas no modelo elaborado. Esse termo $\left(\alpha_{i t}\right)$, por ser composto por variáveis não incluídas no modelo, pode estar relacionado com as variáveis independentes controladas ou não. Nesse sentido, ele pode apresentar efeitos fixos e se correlacionar com as variáveis independentes observadas no modelo, sendo constantes ao longo do tempo, ou pode ser composto por variáveis aleatórias que não têm relação com as demais variáveis e apresentam variações ao longo do tempo. Para determinar o tipo de modelo GLS a ser utilizado, se de efeito fixo ou aleatório, é necessário realizar o teste de Hausman, que testa a hipótese nula de que não existe diferença entre os dois modelos, de forma que os coeficientes são similares. A hipótese alternativa é de que a estimação dos dois modelos é diferente; nesse caso o modelo de efeito fixo deve ser aplicado. Todos os modelos apresentados na seção "Resultados" apresentaram valores de teste de Hausman altos e estatisticamente significativos, por isso escolhemos elaborar modelos de efeitos fixos em vez de aleatórios. Os modelos aleatórios foram suprimidos deste artigo por questão de espaço. Eles estão disponíveis para acesso com os autores. 
valor de uma terceira variável. Na análise que estamos realizando, queremos saber, por exemplo, se a variável independente renda per capita $(X)$ pode estar associada ao aumento ou decréscimo na variável dependente porcentagem de votação para a Câmara (Y) a cada ano eleitoral (Z). Porcentagem de votação e renda per capita são variáveis contínuas, enquanto as dummies de ano eleitoral são variáveis dicotômicas que têm o valor 1 quando a condição está presente (se a dummy se refere ao ano de 1998, por exemplo, ela terá o valor 1 em todos os casos referentes a esse ano) e 0 se está ausente (em todos os demais casos que não se referem ao ano que a dummy está controlando). Se a hipótese for que o aumento em uma unidade da variável independente $X$ representa um aumento na dependente $Y$ na presença de $Z$, ela pode ser representada matematicamente da seguinte forma no modelo GLS apresentado anteriormente:

Equação 2:

$y_{i t}=\mu_{t}+\beta_{1} X+\beta_{2} Z+\beta_{3} X Z+\alpha_{i t}+\varepsilon_{i t}$

Os coeficientes dos termos de primeira ordem das interações multiplicativas, no entanto, não apresentam o efeito marginal de cada variável independente como em modelos de regressão lineares aditivas. Estes coeficientes capturam o efeito de $X$ em $Y$ quando $Z$ é 0 , e vice-versa. Portanto, é necessário calcular o efeito marginal de $X$ em $Y$ para valores substantivos da variável condicionante Z. Gráficos serão elaborados para ilustrar o efeito marginal dos anos eleitorais nas variáveis aqui analisadas.

\section{Resultados}

Elaboramos ao todo seis modelos. No primeiro modelo, variáveis socioeconômicas e políticas foram testadas conjuntamente. No segundo, apenas as socioeconômicas foram incluídas e, no terceiro, apenas as políticas. Os modelos 4 e 5 avaliam a mudança ao longo do tempo das variáveis socioeconômicas que foram estatisticamente significativas no modelo 2, incluindo as interações dessas variáveis com as dummies de ano. Por fim, o modelo 6 avalia o impacto do programa Bolsa Família controlando por todas as variáveis, socioeconômicas e políticas. A Tabela 1 discrimina os resultados dos três primeiros modelos: 
Tabela 1

Modelos de Mínimos Quadrados Generalizados com Efeitos Fixos - Variável dependente: porcentagem da votação do PT para a Câmara dos Deputados por município e ano ${ }^{8}$

\begin{tabular}{|c|c|c|c|}
\hline & Modelo 1 & Modelo 2 & Modelo 3 \\
\hline População urbana (\%) & $\begin{array}{c}0,01 * * * \\
(0,00)\end{array}$ & $\begin{array}{c}0,02 * * * \\
(0,00)\end{array}$ & - \\
\hline Densidade populacional (hab/km²) & $\begin{array}{c}1,12 \\
(0,15)\end{array}$ & $\begin{array}{c}0,90 \\
(0,17)\end{array}$ & - \\
\hline Escolaridade (\%) & $\begin{array}{l}0,005 \\
(0,01)\end{array}$ & $\begin{array}{l}-0,20 \\
(0,01)\end{array}$ & - \\
\hline Renda per capita & $\begin{array}{c}0,77 \\
(0,27)\end{array}$ & $\begin{array}{c}5,47 * * * \\
(0,3)\end{array}$ & - \\
\hline Votação do candidato à presidência & $\begin{array}{c}0,09 * * * \\
(0,00)\end{array}$ & - & $\begin{array}{c}0,09 * * * \\
(0,00)\end{array}$ \\
\hline Participação no governo & $\begin{array}{c}0 \\
\text { (omitido) }\end{array}$ & - & $\begin{array}{c}0 \\
\text { (omitido) }\end{array}$ \\
\hline Presença de governador do partido & $\begin{array}{c}2,72 * * * \\
(0,13)\end{array}$ & - & $\begin{array}{c}2,71 * * * \\
(0,13)\end{array}$ \\
\hline Votação do candidato a governador & $\begin{array}{c}0,14 * * * \\
(0,00)\end{array}$ & - & $\begin{array}{c}0,14 * * * \\
(0,00)\end{array}$ \\
\hline Presença de prefeito do partido & $\begin{array}{c}7,11 * * * \\
(0,16)\end{array}$ & - & $\begin{array}{c}7,11 * * * \\
(0,16)\end{array}$ \\
\hline 1998 & $\begin{array}{c}0,12 \\
(0,13)\end{array}$ & $\begin{array}{c}0,50 * * * \\
(0,14)\end{array}$ & $\begin{array}{c}0,14 \\
(0,11)\end{array}$ \\
\hline 2002 & $\begin{array}{c}2,75 * * * \\
(0,18)\end{array}$ & $\begin{array}{c}6,53 * * * \\
(0,19)\end{array}$ & $\begin{array}{c}2,82 * * * \\
(0,12)\end{array}$ \\
\hline 2006 & $\begin{array}{c}1,49 * * * \\
(0,28)\end{array}$ & $\begin{array}{c}6,12 * * * \\
(0,30)\end{array}$ & $\begin{array}{l}1,6 * * * \\
(0,14)\end{array}$ \\
\hline 2010 & $\begin{array}{c}3,6 * * * \\
(0,38) \\
\end{array}$ & $\begin{array}{c}8,57 * * * \\
(0,41) \\
\end{array}$ & $\begin{array}{c}3,75 * * * \\
(0,15) \\
\end{array}$ \\
\hline 2014 & $\begin{array}{c}1,56 * * * \\
(0,38)\end{array}$ & $\begin{array}{c}7,57 * * * \\
(0,41)\end{array}$ & $\begin{array}{l}1,7 * * * \\
(0,15)\end{array}$ \\
\hline Constante & $\begin{array}{c}1,65 * * * \\
(1,41)\end{array}$ & $\begin{array}{c}1,64 * * * \\
(0,09)\end{array}$ & $\begin{array}{c}-5,71 * * * \\
(1,58)\end{array}$ \\
\hline $\mathrm{R}^{2}$ within & 0,43 & 0,28 & 0,43 \\
\hline$R^{2}$ between & 0,51 & 0,01 & 0,51 \\
\hline $\mathrm{R}^{2}$ overall & 0,43 & 0,15 & 0,43 \\
\hline Rho & 0,42 & 0,48 & 0,42 \\
\hline
\end{tabular}

Fontes: TSE, CEM/Cebrap, IBGE. Cálculo e elaboração dos autores. Nota: Significância estatística ao nível de $* * * \mathrm{p}<0,001 ; * * \mathrm{p}<0,01 ; * \mathrm{p}<0,05$. Erro-padrão entre parênteses.

A análise dos ajustes dos modelos mostra que as variáveis políticas explicam uma variação maior da votação do PT na Câmara do que as variáveis socioeconômicas.

\footnotetext{
${ }^{8}$ Os valores dos coeficientes das variáveis incluídas nos modelos com logs - renda per capita e densidade populacional - já estão exponenciados nas tabelas.
} 
Tanto o modelo 1 , que inclui todas as variáveis, quanto o modelo 3, que controla apenas as variáveis políticas, apresentam $43 \%$ de variância total explicada ( $R^{2}$ overall), sendo que $42 \%$ dessa variância é predita pelo efeito fixo (rho). 0 modelo 2, que controla o efeito das variáveis socioeconômicas, explica apenas $15 \%$ da variância da votação do PT nos municípios. Esses resultados indicam que as variáveis políticas incluídas nos modelos em conjunto possuem maior potencial explicativo sobre a votação do PT nos municípios.

As dummies de ano eleitoral (1998, 2002, 2006, 2010 e 2014) apresentam a evolução do desempenho do PT tendo como referência o ano de 1994. Os modelos 1 e 3 têm coeficientes parecidos e indicam um desempenho variável. Os coeficientes não são significativos para o ano de 1998. No ano de 2002 o partido apresentou um aumento de mais de $2 \%$ de sua votação. Porém, em 2006 o aumento de seu desempenho foi menor, em torno de 1,5\%. Em 2010, o desempenho cresce em patamares maiores, girando em torno de $3,5 \%$. No ano de 2014 , o crescimento foi reduzido, voltando ao patamar de 2006.

No entanto, ao controlarmos apenas as variáveis socioeconômicas no modelo 2, as dummies de ano apresentam coeficientes numericamente mais substantivos, variando na casa dos 6\% entre os anos de 2002 e 2006 e aumentando para 8,5\% em 2010 e $7,5 \%$ em 2014. Assim, apesar de terem influência menor na explicação do voto do PT, representando apenas $15 \%$ da variância explicada na ausência das variáveis políticas (modelo 2), as variáveis socioeconômicas foram importantes para o crescimento da votação nos municípios ao longo do tempo.

Quanto às variáveis políticas, os modelos mostram a importância da presença de membros do partido em cargos executivos subnacionais em seu desempenho nas eleições para a Câmara. A presença de um governador do estado do PT aumenta em média $2,7 \%$ da sua votação, enquanto a presença de um prefeito do partido tem um efeito ainda maior, representando um aumento de $7,1 \%$ na votação para a Câmara. A votação dos candidatos à presidência e aos governos de estado também foram positivas. $\mathrm{O}$ aumento de $1 \%$ na votação do candidato a presidente no primeiro turno significou um aumento de $0,09 \%$ da votação para a Câmara. A votação para governador representou um aumento de $0,1 \%$. A variável participação no governo foi omitida dos modelos por apresentar alta multicolinearidade.

Com relação às variáveis socioeconômicas, apenas duas foram estatisticamente significativas no modelo 2, a porcentagem de população urbana e a renda per capita. Ambas as variáveis apresentam impacto positivo na votação para a Câmara. No modelo 1 , o aumento de $1 \%$ da população urbana representou um aumento de $0,01 \%$ na votação do partido nos municípios, enquanto no modelo 2 esse aumento foi de 0,02\%. Quanto à renda per capita, o modelo 2 mostra que o aumento de um real na renda significou um aumento de 5,47\% na votação do partido na Câmara.

Esses resultados poderiam indicar sentido contrário à hipótese proposta neste artigo. No entanto, os modelos longitudinais apresentam o impacto das variáveis no conjunto dos anos. Dessa forma, é preciso verificar se as características socioeconômicas 
das bases de apoio do PT para a Câmara se modificaram ao longo do tempo. Os modelos 4 e 5 repetem as variáveis controladas no modelo 2, porém incluindo as interações entre as dummies de ano eleitoral e as variáveis porcentagem de população urbana e renda per capita, respectivamente. Os resultados são apresentados na Tabela 2:

Tabela 2

Modelos de Mínimos Quadrados Generalizados com Efeitos Fixos e Interações com variáveis socioeconômicas - Variável dependente: porcentagem da votação do PT para a Câmara dos Deputados por município e ano ${ }^{9}$

\begin{tabular}{|c|c|c|}
\hline & $\begin{array}{l}\text { Modelo } 4 \text { - Interações Ano } \\
\text { e População urbana }\end{array}$ & $\begin{array}{c}\text { Modelo } 5 \text { - Interaç̃̃es Ano } \\
\text { e Renda per capita (log) }\end{array}$ \\
\hline População urbana (\%) & $\begin{array}{c}0,02 * * * \\
(0,00)\end{array}$ & $\begin{array}{c}0,03 * * * \\
(0,00)\end{array}$ \\
\hline $\begin{array}{l}\text { Densidade populacional } \\
\left(\mathrm{hab} / \mathrm{km}^{2}\right)\end{array}$ & $\begin{array}{l}1,37 \\
(0,17)\end{array}$ & $\begin{array}{c}1,82 \\
(0,17)\end{array}$ \\
\hline Escolaridade $(\%)$ & $\begin{array}{c}0,02 \\
(0,01)\end{array}$ & $\begin{array}{l}-0,02 \\
(0,01)\end{array}$ \\
\hline Renda per capita ( $\mathrm{R} \$$ ) & $\begin{array}{c}0,86 \\
(0,31)\end{array}$ & $\begin{array}{c}0,63 \\
(0,31)\end{array}$ \\
\hline 1998 & $\begin{array}{l}-0,13 \\
(0,31)\end{array}$ & $\begin{array}{c}-3,52^{* *} \\
(1,15)\end{array}$ \\
\hline 2002 & $\begin{array}{c}4,29 * * * \\
(0,34)\end{array}$ & $\begin{array}{c}-12,28 * * * \\
(1,18)\end{array}$ \\
\hline 2006 & $\begin{array}{c}7,94 * * * \\
(0,43)\end{array}$ & $\begin{array}{c}13,80 * * * \\
(1,33)\end{array}$ \\
\hline 2010 & $\begin{array}{c}12,74 * * * \\
(0,52)\end{array}$ & $\begin{array}{c}24,68 * * * \\
(1,43)\end{array}$ \\
\hline 2014 & $\begin{array}{c}13,47 * * * \\
(0,52)\end{array}$ & $\begin{array}{c}26,86 * * * \\
(1,43)\end{array}$ \\
\hline $\begin{array}{l}\text { Interação variável socioeconômica } \\
\text { e } 1998\end{array}$ & $\begin{array}{l}0,01^{* *} \\
(0,00)\end{array}$ & $\begin{array}{c}0,80 * * * \\
(0,21)\end{array}$ \\
\hline $\begin{array}{l}\text { Interação variável socioeconômica } \\
\text { e } 2002\end{array}$ & $\begin{array}{c}0,04 * * * \\
(0,00)\end{array}$ & $\begin{array}{c}3,45 * * * \\
(0,21)\end{array}$ \\
\hline $\begin{array}{l}\text { Interação variável socioeconômica } \\
\text { e } 2006\end{array}$ & $\begin{aligned}-0,02 * * * \\
\\
(0,00)\end{aligned}$ & $\begin{array}{c}-1,09 * * * \\
(0,23)\end{array}$ \\
\hline $\begin{array}{l}\text { Interação variável socioeconômica } \\
\text { e } 2010\end{array}$ & $\begin{array}{c}-0,06 * * * \\
(0,00)\end{array}$ & $\begin{array}{c}-2,38^{* * *} \\
(0,24)\end{array}$ \\
\hline $\begin{array}{l}\text { Interação variável socioeconômica } \\
\text { e } 2014\end{array}$ & $\begin{array}{c}-0.08 * * * \\
(0,00)\end{array}$ & $\begin{array}{c}-2,90 * * * \\
(0,24)\end{array}$ \\
\hline Constante & $\begin{array}{c}2,01 * * * \\
(1,60)\end{array}$ & $\begin{array}{c}4,99 * * \\
(1,64)\end{array}$ \\
\hline $\mathrm{R}^{2}$ Within & 0,29 & 0,30 \\
\hline $\mathrm{R}^{2}$ Between & 0,01 & 0,03 \\
\hline $\mathrm{R}^{2}$ Overall & 0,16 & 0,14 \\
\hline Rho & 0,49 & 0,51 \\
\hline
\end{tabular}

Fontes: TSE, CEM/Cebrap, IBGE. Cálculo e elaboração dos autores.

Nota: Significância estatística ao nível de $* * * p<0,001 ; * * p<0,01 ; * p<0,05$. Erro-padrão entre parênteses.

\footnotetext{
${ }^{9}$ Optamos por desenvolver os modelos com as interações com base no modelo 2 e não com o modelo completo 1 para que fossem mais parcimoniosos, mesmo com o prejuízo de não controlar o efeito das variáveis políticas. Os coeficientes das variáveis que foram logaritmizadas para a elaboração do modelo densidade populacional e renda per capita - são apresentados na tabela exponenciados.
} 
Como explicado na seção "Tratamento de dados e métodos", os termos de primeira ordem das interações estão captando o efeito da população urbana e da renda per capita sobre a votação quando as variáveis dummies de ano eleitoral têm o valor zero. O mesmo ocorre com os coeficientes das dummies; elas estão captando o efeito do ano eleitoral sobre o voto quando a população urbana ou a renda per capita têm valor igual a zero. Os coeficientes dos termos das interações, nesse sentido, não apresentam interpretação substantiva, uma vez que não existem municípios com população urbana ou renda per capita com valor zero.

No entanto, as interações em si apresentam o impacto de cada uma dessas variáveis no ano eleitoral controlado, permitindo observar a mudança do efeito delas com o passar dos anos. Em ambos os modelos as interações são estatisticamente significativas e seus coeficientes indicam uma mudança na relação entre as variáveis socioeconômicas e a votação do PT a partir do ano de 2006. As interações entre ano e renda per capita são as que apresentam maior impacto; em 2002 o aumento de uma unidade do log da renda per capita correspondeu ao aumento de 3,45\% na votação para a Câmara. Porém, em 2006 o aumento de uma unidade do log da renda representou um decréscimo na votação do PT em $1 \%$. A relação negativa entre renda e voto se manteve nas eleições de 2010 e 2014, correspondendo a um decréscimo de 2,3\% e 2,9\% na votação para o aumento de uma unidade do log da renda.

Uma vez que os termos primários das interações não fornecem interpretação substantiva, para obtermos alguma informação sobre essas variáveis elaboramos os Gráficos 6 e 7 com o efeito marginal delas, tendo 1994 como ano de referência: 


\section{Gráfico 6 \\ Efeito marginal da porcentagem de população urbana sobre a votação do PT na Câmara dos Deputados por ano eleitoral}
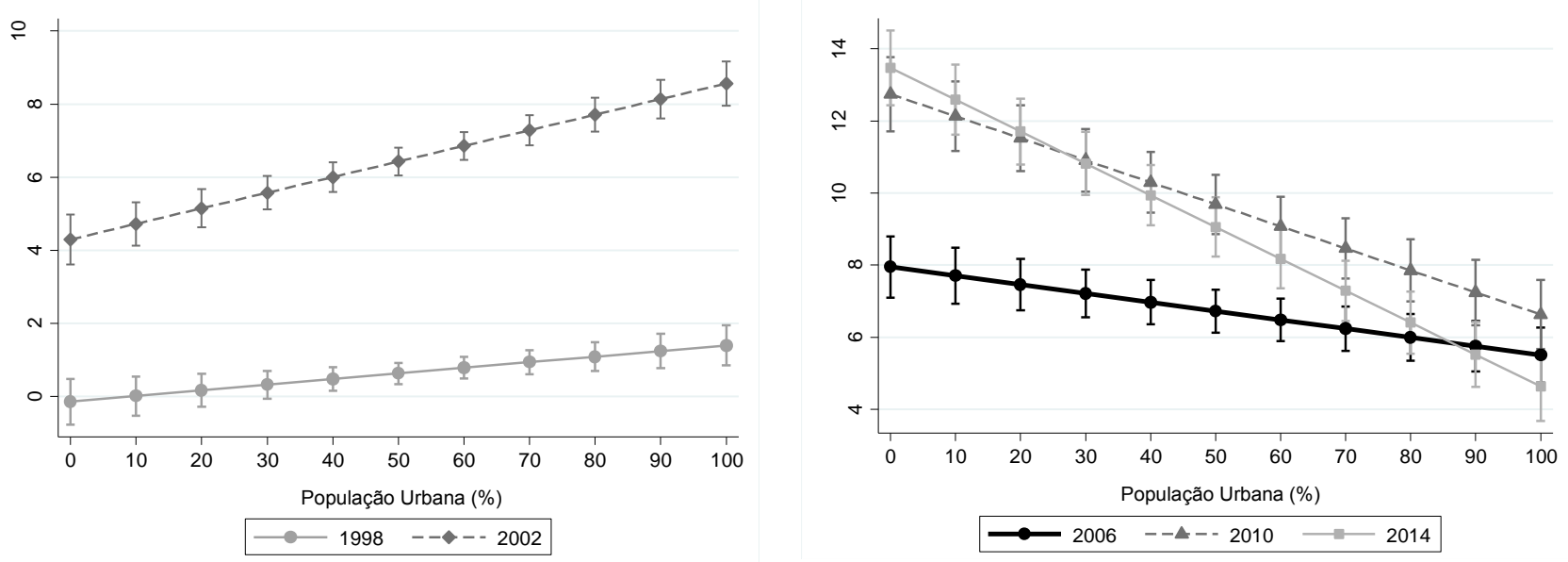

Fontes: TSE, CEM/Cebrap, IBGE. Cálculo e elaboração da autora. Nota: Intervalo de confiança a 95\%.

Gráfico 7

Efeito marginal da porcentagem da renda per capita sobre a votação do PT na Câmara dos Deputados por ano eleitoral

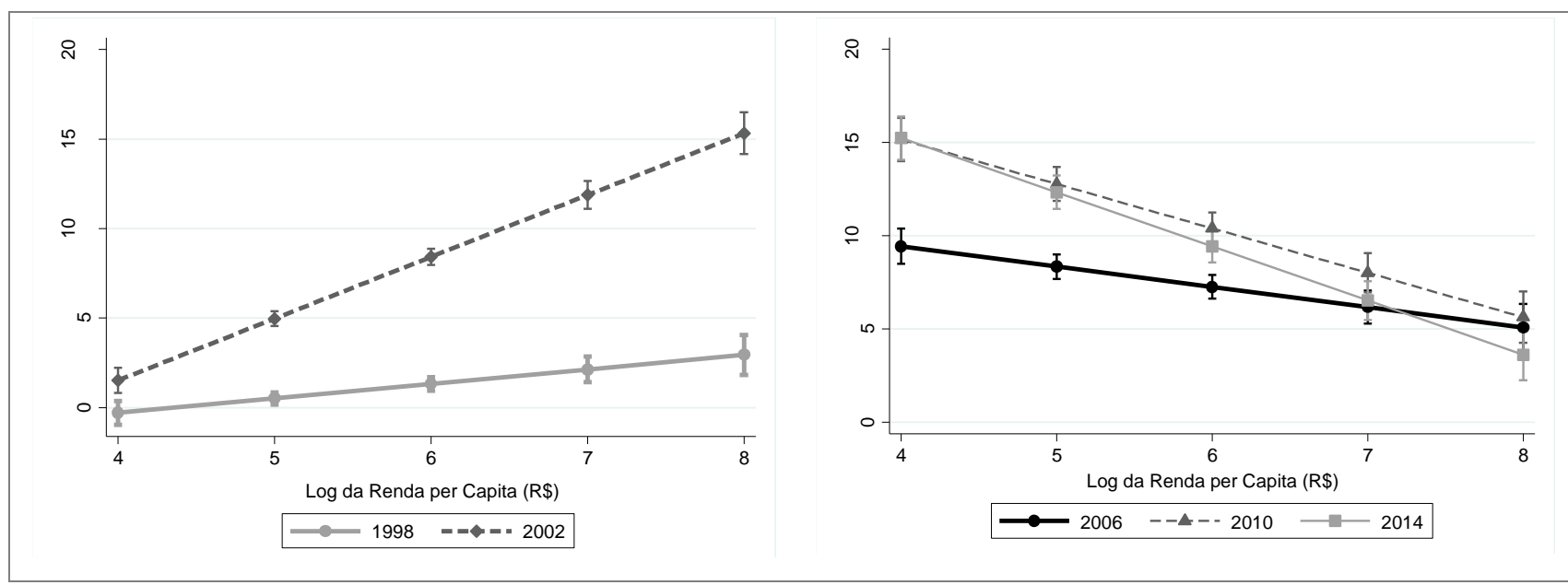

Fontes: TSE, CEM/Cebrap, IBGE. Cálculo e elaboração da autora.

Nota: Intervalo de confiança a $95 \%$.

Os gráficos demonstram uma mudança na evolução do impacto das variáveis renda e população urbana sobre o voto. Nos anos de 1998 e 2002 a votação do PT para a 
Câmara era maior em municípios mais urbanizados e com maior renda per capita ${ }^{10}$. Nas últimas três eleições (2006, 2010 e 2014) o partido passou a apresentar votação maior em municípios com renda per capita e porcentagem de população urbana mais baixas. A sobreposição das curvas e dos intervalos de confiança nesses anos indica que a diferença das votações entre um ano e outro não é significativa, apesar de a estatística de cada ano ser. Em suma, a mudança da inclinação das curvas entre os anos de 2002 e 2006 e a continuação dessa tendência nas eleições seguintes demonstram a mudança das características socioeconômicas das bases de apoio do PT na Câmara.

A tese do divórcio entre as bases eleitorais do lulismo e do petismo sustentada no artigo de Terron e Soares (2010) utiliza métodos de análise espacial. As análises das bases sociais desenvolvidas neste artigo demonstram que essa separação é apenas espacial/territorial; as variáveis socioeconômicas da votação para a Câmara seguem a direção da votação de Lula em 2006. Isso quer dizer que outros municípios com características socioeconômicas similares aos das bases sociais de Lula também apresentaram alta votação no PT para a Câmara. O Índice de Moran Local utilizado pelos autores calcula a correlação entre o voto, as variáveis socioeconômicas e uma matriz de vizinhança. Pode-se esperar, no entanto, que o partido tenha sido bem votado em outras áreas em que o efeito de vizinhança não é estatisticamente significativo, porém onde as características socioeconômicas são similares às do voto para presidente.

Enquanto o trabalho de Terron e Soares (2010) tem como principal contribuição incluir o território e a vizinhança como fatores relevantes para a compreensão do desempenho eleitoral de Lula e do PT em seus modelos de regressão, o presente artigo inova ao controlar o tempo nos modelos que avaliam a votação do partido para a Câmara. Os modelos longitudinais e a análise do efeito marginal das variáveis independentes de interesse permitem verificar alterações nas características socioeconômicas dos municípios em que o partido foi bem votado de forma que não foi possível verificar apenas controlando o espaço. Nesse sentido, concluímos em sentido diferente a tese do divórcio entre o lulismo e o petismo sustentada por Terron e Soares (2010). No longo prazo, especialmente incorporando dados das eleições de 2010 e 2014, há uma reaproximação gradativa nas características socioeconômicas das bases eleitorais do Iulismo e do petismo.

O modelo 6, apresentado na Tabela 3, testa, justamente pela atenção recebida pela literatura, o efeito do impacto do programa Bolsa Família na votação do partido nas eleições para a Câmara dos Deputados. O período analisado é reduzido, abarcando apenas as eleições em que o programa já havia sido implantado, quais sejam, os anos de 2006, 2010 e 2014. O ano de referência é 2006. A variável renda per capita foi retirada para que não constassem duas variáveis de renda no modelo.

\footnotetext{
${ }^{10}$ A estatística não é significativa para valores de renda per capita e porcentagem de população urbana em que a reta de predição ou os intervalos de confiança cortam o valor zero no eixo Y. Para o ano de 1998 , a estatística não é significativa para os municípios com índices mais baixos de urbanização e renda.
} 
Tabela 3

Modelos de Mínimos Quadrados Generalizados com Efeitos Fixos - Variável dependente: porcentagem da votação do PT para a Câmara dos Deputados por município e ano. Controle: Impacto do Bolsa Família sobre a Renda

\begin{tabular}{|c|c|}
\hline & Modelo 6 \\
\hline População urbana (\%) & $\begin{array}{c}0,02 \\
(0,02)\end{array}$ \\
\hline Densidade populacional (hab/km²) & $\begin{array}{c}1,41 \\
(0,86)\end{array}$ \\
\hline Escolaridade (\%) & $\begin{array}{l}-0,16 * * * \\
(0,05)\end{array}$ \\
\hline Votação do candidato à presidência & $\begin{array}{c}0,12 * * * \\
(0,00)\end{array}$ \\
\hline Presença de governador do partido & $\begin{array}{c}2,39 * * * \\
(0,20)\end{array}$ \\
\hline Votação do candidato a governador & $\begin{array}{l}0,09 * * * \\
(0,00)\end{array}$ \\
\hline Presença de prefeito do partido & $\begin{array}{c}4,96 * * * \\
(0,23)\end{array}$ \\
\hline $\begin{array}{l}\text { Impacto do Bolsa Família sobre a renda per } \\
\text { capita }\end{array}$ & $\begin{array}{l}-5,25 e^{-06} \\
\left(8,40 e^{-06}\right)\end{array}$ \\
\hline 2010 & $\begin{array}{c}3,28 * * * \\
(0,40)\end{array}$ \\
\hline 2014 & $\begin{array}{c}1,73 * * * \\
(0,41)\end{array}$ \\
\hline Constante & $\begin{array}{c}5,60 \\
(2,92)\end{array}$ \\
\hline $\mathrm{R}^{2}$ within & 0,15 \\
\hline $\mathrm{R}^{2}$ between & 0,19 \\
\hline $\mathrm{R}^{2}$ overall & 0,18 \\
\hline Rho & 0,61 \\
\hline
\end{tabular}

Fontes: TSE, CEM/Cebrap, IBGE, Ministério da Assistência Social. Cálculo e elaboração dos autores.

Nota: Significância estatística ao nível de $* * * \mathrm{p}<0,001 ; * * \mathrm{p}<0,01 ; * \mathrm{p}<0,05$. Erro-padrão entre parênteses. 
O modelo da Tabela 3 mostra que o programa Bolsa Família não apresenta relação estatisticamente significativa com a votação do partido na Câmara dos Deputados. Esse resultado converge com análises realizadas anteriormente pela literatura (Terron e Soares, 2010; Zucco, 2013) ${ }^{11}$. Todas as outras variáveis políticas do modelo possuem significância estatística e relação positiva com a votação do partido. 0 PT apresenta melhor desempenho para a Câmara dos Deputados de acordo com o crescimento da votação dos seus candidatos à presidência e aos governos de estado, assim como amplia sua votação de acordo com a presença de governador e de prefeito do partido no momento da eleição. Esses resultados, lidos em conjunto com os modelos tratados acima, indicam que o bom desempenho eleitoral do PT e sua presença em cargos executivos subnacionais são os principais fatores explicativos para sua votação para a Câmara.

\section{Conclusão}

Este artigo teve como objetivo suprir uma lacuna encontrada na literatura sobre eleições no Brasil em relação à votação do PT para a Câmara dos Deputados. Seu propósito foi trazer novos elementos para a compreensão do desempenho eleitoral desse partido, avaliando se faria sentido pensar em uma disjuntiva entre o petismo e o lulismo do ponto de vista eleitoral, como propõe parte da literatura. A partir dessa investigação, seria possível refletir a respeito dos impactos de estar 12 anos à frente da presidência da República sobre um partido político caracterizado, no contexto de seu surgimento, como experiência única de partido de massas na história brasileira, constituído a partir das grandes metrópoles urbanas e com fortes laços com setores organizados da sociedade civil brasileira (Meneguello, 1989). Para além de verificar a base social de sua votação, também se tornou importante analisar quais variáveis possuíam maior capacidade de explicação sobre o desempenho eleitoral do PT na Câmara dos Deputados.

Nossos resultados corroboram a hipótese do artigo. A partir de 2006, o perfil socioeconômico e demográfico das bases territoriais de apoio da votação do PT começa a sofrer alterações que seriam intensificadas nas eleições seguintes. Essas alterações caminham em sentido convergente com a mudança observada pela literatura ao abordar os votos de Lula na sua reeleição. Em outras palavras, o voto no PT cresce em cidades de menor contingente populacional e amplia seu desempenho na região Nordeste, assim

\footnotetext{
${ }^{11}$ Com vistas a testar outras especificações para a variável Bolsa Família, também geramos modelos usando a cobertura do programa no nível municipal como variável independente. Nesse caso, em vez de utilizar a razão entre o gasto no programa e a renda per capita do município, utilizamos a razão entre o total de famílias no programa e o total de famílias no nível municipal. Os resultados demonstram que a cobertura do programa está negativamente relacionada à votação do PT na Câmara, reforçando os argumentos aqui apresentados e conferindo maior robustez metodológica e teórica aos achados deste artigo. Ambas as especificações são utilizadas por Zucco (2013) ao discutir o impacto do Bolsa Família nas eleições para presidente. Esse segundo modelo, que utiliza a cobertura do Bolsa Família, está disponível para consulta caso solicitado aos autores.
} 
como exibe melhores resultados de acordo com a diminuição da renda per capita e taxa de urbanização dos municípios. Assim, a disjuntiva entre lulismo e petismo do ponto de vista eleitoral vem se diluindo, levando-nos à conclusão de que essa separação se encontra cada vez mais datada aos fatores presentes no pleito de 2006.

Chamam atenção os resultados das variáveis políticas sobre o desempenho eleitoral do PT na Câmara. O programa Bolsa Família não apresentou impacto na votação. Em contrapartida, a presença do prefeito do PT no município aparece como principal variável capaz de explicar o desempenho eleitoral dos seus candidatos à Câmara dos Deputados.

É preciso investigar com maior profundidade esses achados. Nossa intuição constituída com forte evidência nos dados aqui apresentados - diz que o acesso à máquina pública subnacional vem se tornando elemento central para o sucesso eleitoral do PT. A partir de sua chegada à presidência da República, o partido tem avançado eleitoralmente rumo às prefeituras de cidades menores, sobretudo na região Nordeste. Uma hipótese levantada a partir deste artigo, e que merece atenção em estudos futuros, é que a evolução da presença do partido em cargos subnacionais tem sido a ponte para a mudança da distribuição demográfica e socioeconômica da votação do PT. Ao lado desse fenômeno, o recorrente envolvimento de lideranças do partido em denúncias de corrupção parece afastar cada vez mais seus candidatos das grandes cidades brasileiras.

Quando se considera o comportamento das bases eleitorais no Legislativo, a tese da racionalidade econômica para a explicação do voto do PT pode ser questionada pelos resultados aqui apresentados. Não parece haver conexão entre melhoria de vida da população e recompensa aos deputados do PT, dada a ausência de impacto do programa Bolsa Família como mecanismo causal entre essas duas variáveis. Mais importante, parecem ser as variáveis políticas os mecanismos que agem com maior peso nessa expansão do PT rumo a novas bases eleitorais.

Nesse sentido, se nos pleitos presidenciais as bases do PT foram alteradas pela via da inclusão social e distribuição de renda, principalmente por meio do programa Bolsa Família, garantindo assim uma recompensa por parte dos eleitores mais pobres capaz de consagrar seus candidatos vitoriosos nas três eleições presidenciais seguintes, no que tange à Câmara dos Deputados, sua votação parece se sustentar sobre bases mais frágeis e de impacto mais arriscado na trajetória histórica do partido. Ser recompensado por eleitores pobres que ascenderam socialmente converge perfeitamente com objetivos estratégicos da fundação do PT. Porém, essa recompensa parece não atingir o partido como um todo, com seu desempenho eleitoral para o Legislativo federal dependendo fortemente da presença de prefeitos e governadores do partido nos municípios e estados. Portanto, as explicações da mudança de bases eleitorais entre lulismo e petismo parecem seguir lógicas distintas. Essa diferença pode trazer riscos à trajetória do PT enquanto partido político único na recente história democrática brasileira.

Por fim, acreditamos que este artigo sugere algumas questões para futura investigação. Em primeiro lugar, há de se aprofundar a análise do impacto das variáveis 
políticas no comportamento eleitoral do PT, dando maior atenção a sua evolução no tempo e a sua interação com fatores econômicos e sociais. Em segundo lugar, é necessário identificar quais são os impactos da mudança de bases eleitorais no perfil dos deputados petistas eleitos. Em terceiro lugar, é importante avançar ainda mais na compreensão de como se dão as relações intragovernamentais no federalismo e seus impactos eleitorais. Em particular, cabe investigar se é possível generalizar o fenômeno aqui descrito para outros níveis federativos, assim como para outros partidos políticos brasileiros.

Natalia Maciel - Pesquisadora do Doxa: Laboratório de Estudos Eleitorais, em Comunicação Política e Opinião Pública. Instituto de Estudos Sociais e Políticos. Universidade do Estado do Rio de Janeiro. E-mail: <nmaciel@iesp.uerj.br>.

Tiago Ventura - Doutorando em Ciência Política pela Universidade de Maryland - College Park, e pelo Instituto de Estudos Sociais e Políticos, Universidade do Estado do Rio de Janeiro. E-mail: <tiago.ventura@iesp.uerj.br>.

\section{Referências bibliográficas}

Agnew, J. "Maps and models in political studies: a reply to comments". Political Geography, vol. 15, no 2, p. $165-167,1996$.

AMES, B. Os entraves da democracia no Brasil. Rio de Janeiro: FGV Editora, 2003.

Avelino, G.; Biderman, C.; BARONE, L. "Articulações intrapartidárias e desempenho eleitoral no Brasil". Dados - Revista de Ciências Sociais, vol. 55, no 4, p. 987-1.013, 2012.

BoHn, S. "Social policy and vote in Brazil: Bolsa Família and the shifts in Lula's electoral base". Latin American Research Review, vol. 46, no 1, p. 54-79, 2011.

Burbank, M. J. "The psychological basis of contextual effects". Political Geography, vol. 14, nº 6-7, p. 621-635, 1995.

CARRARO, A., et al. "É a economia, companheiro: uma análise empírica da reeleição de Lula com base em dados municipais". IBMEC MG Working Paper, WP-41, 2007.

CARvalho, N. R. E no início eram as bases: geografia política do voto e comportamento legislativo no Brasil. Rio de Janeiro: Revan, 2003.

Cox, G. Making votes count: strategic coordination in the world's electoral systems. Cambridge/New York: Cambridge University Press, 1997.

Hunter, W.; POWer, T. "Rewarding Lula: Executive Power, social policy, and the Brazilian elections of 2006". Latin American Politics and Society, vol. 49, no 1, p. 1-30, 2007.

Johnston, R.; PATtie, C. Putting voters in their place: geography and elections in Great Britain. Oxford: Oxford University Press, 2006.

Meneguello, R. PT: a formação de um partido, 1979-1982. Rio de Janeiro: Paz e Terra, 1989. 
NiCOLAU, J. "Eleições presidenciais nos municípios brasileiros: uma breve comparação dos resultados do primeiro turno de 2010 e 2014". Em Debate, vol. 7, no 2, p. 29-41, 2015.

Nicolau, J.; Peixoto, V. "Uma disputa em três tempos: uma análise das bases municipais das eleições presidenciais de 2006". In: Anais do XXXI Encontro Anual da Anpocs, Caxambu, 2007.

Nunes, M. C.; Giani, M.; Resende, J. F. "2010 electoral scenario: changes and continuities in the postLula Brazilian electoral behavior". In: Anais do Evento WAPOR 63rd Annual Meeting, Chicago, 2010.

Rennó, L.; CABello, A. "As bases do Lulismo: a volta do personalismo, realinhamento ideológico ou não alinhamento?". Revista Brasileira de Ciências Sociais, vol. 25, no 74, p. 39-60, 2010.

RICCI, R. Lulismo: da era dos movimentos sociais à ascensão da nova classe média brasileira. Rio de Janeiro: Contraponto, 2010.

SAMUELS, D. Ambition, federalism, and legislative politics in Brazil. New York: Cambridge University Press, 2003. 2, p. 1-27, 2006.

"Sources of mass partisanship in Brazil". Latin American Politics and Society, vol. 48, no

SAmuels, D.; ZuCCO, C. "Lulismo, petismo, and the future of Brazilian politics". Journal of Politics in Latin America, vol. 3, p. 129-158, 2014.

Shugart, M.; Carey, J. Presidents and assemblies: constitutional design and electoral dynamics. Cambrigde: Cambridge University Press, 1992.

Singer, A. Os sentidos do lulismo: reforma gradual e pacto conservador. São Paulo: Companhia das Letras, 2012.

SOARES, G. Sociedade e política no Brasil: desenvolvimento, classe e política durante a Segunda República. São Paulo: Difusão Européia, 1973.

SOARES, G.; TERRON, S. "Dois Lulas: a geografia eleitoral da reeleição (explorando conceitos, métodos e técnicas de análise geoespacial". Opinião Pública, vol. 14, nº 2, p. 269-301, 2008.

TerRon, S. "Geografia eleitoral em foco". Em Debate, vol. 4, no 2, p. 8-18, 2012.

Terron, S.; SoARES, G. "As bases eleitorais de Lula e do PT: do distanciamento ao divórcio". Opinião Pública, vol. 16, n 2, p. 310-337, 2010.

VEIGA, L. "Os partidos brasileiros na perspectiva dos eleitores: mudanças e continuidades na identificação partidária e na avaliação das principais legendas após 2002". Opinião Pública, vol. 13, no 2, p. 340-365, 2007.

VENTURI, G. "PT 30 anos: crescimento e mudanças na preferência partidária. Impacto nas eleições de 2010". Perseu: História, Memória e Política, vol. 5, p. 197-214, 2010.

Zucco, C. J. "The president's 'new' constituency: Lula and the pragmatic vote in Brazil's 2006 presidential elections". Journal of Latin American Studies, vol. 40, no 1, p. 29-49, 2008.

"When payouts pay off: conditional cash transfers and voting behavior in Brazil 20022010". American Journal of Political Science, vol. 47, no 3, p. 810-822, 2013.

Zucco, C. J.; Power, T. "Bolsa Família and the shift in Lula's electoral base, 2002-2006: a reply to Bohn". Latin American Research Review, vol. 48, n 2, p. 3-24, 2013. 


\section{Resumo}

O Partido dos Trabalhadores na Câmara dos Deputados: a evolução das bases socioeconômicas e territoriais (1994-2014)

Este artigo analisa a evolução das bases eleitorais do Partido dos Trabalhadores para a Câmara dos Deputados no período de 1994 a 2014. Utilizando análise descritiva e modelos longitudinais com dados municipais, verificamos uma alteração dessas bases em direção a cidades com menor população e renda per capita mais baixa, localizadas, sobretudo, no Nordeste brasileiro. Demonstramos que as bases eleitorais do PT para a Câmara sofreram mudanças semelhantes às de seus candidatos à presidência. No entanto, ao contrário dos seus presidenciáveis, o programa Bolsa Família não possui poder explicativo sobre a votação para essa casa legislativa. Encontramos na presença do partido em executivos locais e na sua votação para governador e presidente indicadores mais relevantes de seu desempenho.

Palavras-chave: comportamento eleitoral; Câmara dos Deputados; bases eleitorais; Partidos dos Trabalhadores

\section{Abstract}

The Workers' Party in the Chamber of Deputies: the evolution of the socioeconomic and territorial bases (1994-2014)

This article analyzes the evolution of the Workers' Party's (PT) electoral bases in the disputes for the Chamber of Deputies between 1994 and 2014. Using descriptive analysis and longitudinal models, we find that these bases are changing toward smaller cities with a lower per capita income, located, primarily, in northeastern Brazil. We show that the PT's electoral bases for the Chamber of Deputies and presidency have experienced similar changes. However, while Bolsa Família influences support for the party's presidential candidates, it has no impact on support for its candidates in the Chamber. Instead, we find that the party's presence in subnational executives and its voting in gubernatorial and presidential elections are more relevant indicators of its performance.

Keywords: electoral behavior; Chamber of Deputies; electoral bases; Workers' Party

\section{Resumen}

El Partido de los Trabajadores en la Cámara de los Diputados: la evolución de las bases socioeconómicas y territoriales (1994-2014)

En este artículo se analiza la evolución de las bases electorales del Partido de los Trabajadores en la Cámara de los Diputados de 1994 a 2014. Utilizando el análisis descriptivo y modelos longitudinales con datos locales, vemos un cambio de estas bases para ciudades con menor población y renta per cápita más baja, que se encuentra principalmente en el noreste de Brasil. Hemos demostrado que las bases electorales del PT en la Cámara experimentaron cambios similares a de sus candidatos presidenciales. Sin embargo, a diferencia de sus candidatos presidenciales, el programa Bolsa Familia no tiene poder explicativo sobre el voto para esta casa legislativa. Los indicadores más relevantes de su desempeño son la presencia del partido en los ejecutivos locales y su voto para los candidatos a gobernador del estado y a la presidencia.

Palabras-clave: voto; Cámara de los Diputados; bases electorales; Partido de los Trabajadores 


\section{Résumé}

Le Partido dos Trabalhadores à la Chambre des Députés: l'évolution des bases socio-économiques et territoriales (1994-2014)

Cet article analyse l'évolution des bases électorales du Partido dos Trabalhadores à la Chambre des députés entre 1994 et 2014. A l'aide d'une analyse descriptive et de modèles longitudinaux avec des données municipales, nous constatons que ces bases évoluent vers des villes plus petites, avec un revenu par habitant inférieur, se situant surtout au Nord-est du Brésil. Nous montrons que les bases électorales du PT pour la Chambre des députés et pour la présidence ont connu des changements similaires. Cependant, alors que Bolsa Família influence le soutien aux candidats présidentiels du parti, cela n'a aucun impact sur le soutien de ses candidats à la Chambre. Nous constatons que la présence du parti chez les cadres locaux et son vote aux élections présidentielles et aux postes de gouverneur sont les indicateurs les plus pertinents de sa performance.

Mots-clés: comportement électoral; Chambre des Députés; bases électorales; Parti des Travailleurs

Artigo submetido à publicação em 7 de setembro de 2015. Versão final aprovada em 21 de fevereiro de 2017. 